\title{
Tracking of geodetic height of sea level in the west of Java Sea, Indonesia: A preliminary assessment
}

\author{
Poerbandono* ${ }^{*}$ Kosasih Prijatna, and Irwan Gumilar \\ Geodesy and Geomatics Engineering, Faculty of Earth Sciences and Technology, Institut Teknologi Bandung, Indonesia
}

\begin{abstract}
This paper assesses the agreement between observed heights of sea level from Global Navigation Satellite System (GNSS) and a global model of Mean Sea Surface (MSS). The assessment of the agreement is carried out according to the direct comparison between the height of MSS model and the geodetic height of actual sea level. Here, MSS is generated according to Gravity Recovery And Climate Experiment (GRACE) Gravity Model (GGM) and Mean Dynamic Ocean Topography (MDOT). The tracking of geodetic heights of actual sea level are done by Wide Area Differential (WA D) and Real Time Precise Point Positioning (RTPPP) Global Navigation Satellite System (GNSS) along an approximately 180 Nm SW-NE transect of away-return ship track in the west of the Java Sea, Indonesia. It is found that the overall agreement between geodetic height of sea level and MSS observed by WA DGNSS is $7.5 \mathrm{~cm}$ (away tracking), while those observed by RTPPP GNSS is $39.5 \mathrm{~cm}$ (away tracking) and $36.0 \mathrm{~cm}$ (return tracking). This work recommends selection of the best-fit tide model and careful examination on the dynamics of antenna offset due to vessel attitude.
\end{abstract}

\section{Introduction}

Mean Sea Level (MSL) is an essential element of a National Spatial Reference System (NSRS), which is a part of a National Spatial Data Infrastructure (NSDI) [1, 2]. Along with the other standard tidal datum, such as Highest Astronomical Tide (HAT) and Lowest Astronomical Tide (LAT), MSL defines coastlines from which various rights of ownership of dry lands across supra-, inter-, and sub-tidal areas are delineated [3, 4]. Navigation and offshore construction also demand MSL, respectively to determine the vertical separation to chart datum [5] and as a reference plane for design criteria [6]. Within an NSRS, all of these datums are compiled in the so-called hydrographic separation model [7].

This work is actually a milestone of a roadmap towards the construction of a hydrographic separation model for the domain presented here. A hydrographic separation model defines direct transformation among various vertical datum, primarily between the ellipsoid and the required tidal datum (i.e. LAT, MSL), as well as the geoid and/or another Chart Datum [8, 9]. Earlier work in the same working area on the construction of such a model discusses the spatial distribution of LAT with respect to MSL [10]. For the model to be constructed, a definition of MSL above ellipsoid must be made available. Traditionally, MSL refers to zero-gauge. Here, the term MSS is used as the height of MSL with respect to reference ellipsoid, i.e. World Geodetic System 1984 (WGS84).

It is the intention of this paper in investigating how global MSS might be used for the development of the hydrographic separation model. The work presented in this paper aims at quantifying the discrepancy of a global MSS model with respect to geodetically observed sea level. As advised by The International Federation of Surveyors [11], knowing the errors of such model is one of key factors in understanding the accuracy the data. Here, we investigate an MSS model for the west of Java Sea, Indonesia and compare it with geodetic height of sea level along the survey track (Figure 1).

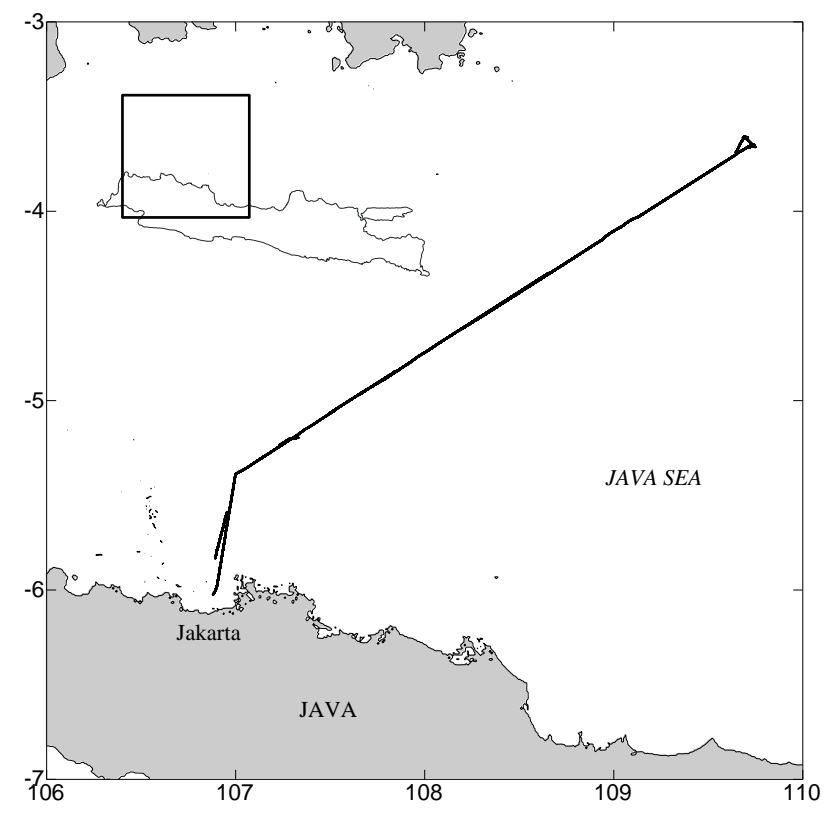

Fig. 1. Study location with track of SW-NE survey transect.

\footnotetext{
*Corresponding author: poerbandono@itb.ac.id
} 


\section{Materials and methods}

The comparison between the MSS model and the geodetic height of sea level is carried out by tracking of actual height of sea surface. The tracking of the actual height of sea surface is carried out during a cruise of Survey Vessel (SV) Explora Nusantara. It is actually an additional mission to the cruise, which make use of vessel's transit away from Jakarta (Tanjung Priok) port to two survey sites NW of Jakarta and return. The away transect occupies a transit length of about $337 \mathrm{~km}$ long (including tracks of survey routes), while the return one occupies roughly $189 \mathrm{~km}$ in length of transit only.

During the tracking, actual height of sea surface is observed by Wide Area Differential (WA D) and Real Time Precise Point Positioning (RTPPP) Global Navigation Satellite System (GNSS). Here, we use standard position output of WA DGNSS C-Nav and RTPPP GNSS Trimble NetR9 systems, i.e. date, time, latitude, longitude, height. $\mathrm{C}-\mathrm{Nav}$ is a commercial positioning service developed according to a proprietary differential GNSS. It utilizes corrections from several base stations to fix carrier phase ambiguities. Trimble NetR9 is a single GNSS receiver facilitated by real time corrections due to satellite's orbit, clock, and phase centre offset.

C-Nav is used only along the away transit, while Trimble NetR9 is used along the away and return transits. Antenna heights of both systems with respect to the sea surface are known as they are measured once upon the installation. Table 1 shows the deployment setting of the both systems. In Figure 2, sketch of installation diagram of the WA DGNSS and RTPPP GNSS onboard SV Explora Nusantara is shown. The heights of the antenna of the WA DGNSS and RTPPP GNSS receivers are respectively $3.59 \mathrm{~m}$ and $6.80 \mathrm{~m}$.

Table 1. Deployment setting of the WA DGNSS and RTPPP GNSS devices

\begin{tabular}{|l|c|c|}
\hline Method & WA DGNSS & RTPPP GNSS \\
\hline Device & C-Nav & Trimble NetR9 \\
\hline $\begin{array}{l}\text { Antenna } \\
\text { height }\end{array}$ & $3.59 \mathrm{~m}$ & $6.80 \mathrm{~m}$ \\
\hline Date & $1-3$ April 2016 & $1-6$ April 2016 \\
\hline $\begin{array}{l}\text { Acquisition } \\
\text { interval }\end{array}$ & $10 \mathrm{~s}$ & $2 \mathrm{~s}$ \\
\hline
\end{tabular}

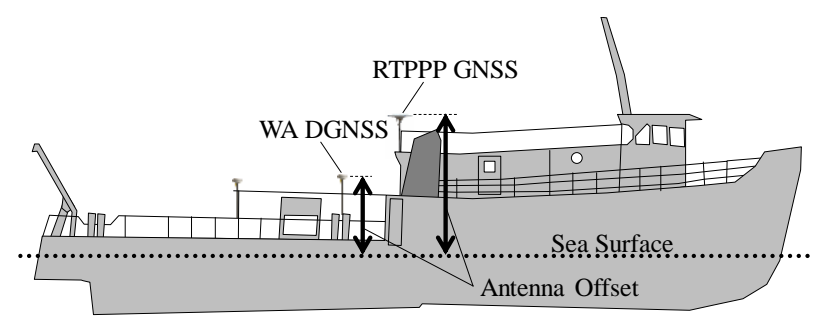

Fig. 2. Installation diagram of WA DGNSS and RTPPP GNSS antennas onboard of SV Explora Nusantara.
For the generation the MSS model, we combine Gravity Recovery And Climate Experiment (GRACE) Gravity Model (GGM) 02C geoid undulation $(N)$ from the International Centre for Global Earth Models (ICGEM) [12, 13] extracted at 0.25 arc-degree spatial resolution. Mean Dynamic Ocean Topography (MDOT) data published by the Asia-Pacific Data Research Centre [14] is combined with the geoid undulation. The MSS model is hence obtained by [15]:

$$
\text { MSS }=N+\text { MDOT }
$$

with MSS $=$ Mean Sea Surface, $N=$ geoid undulation, and MDOT = Mean Dynamic Ocean Topography. The model of MSS is compared with the observed geodetic height of actual sea level $\left(h_{\mathrm{SL}}\right)$ in which a deviation $(\Delta h)$ is expected, so that:

$$
\Delta h(\lambda, \varphi)=h_{\mathrm{SL}}(\lambda, \varphi)-\operatorname{MSS}(\lambda, \varphi)
$$

with $\Delta h(\lambda, \varphi)=$ the deviation between observed height of sea level and MSS at a given position, $\varphi=$ latitude, $\lambda=$ longitude, $h_{S L}(\lambda, \varphi)=$ height of sea level at a given position, and $\operatorname{MSS}(\lambda, \varphi)=$ MSS at a given position. We then consider the overall deviation between observed heights of sea level and MSS $(\dot{h})$ as a systematic vertical offset between both surfaces along the track:

$$
\dot{h}=\frac{1}{S} \int_{0}^{S} \Delta h(s) d s
$$

with $\dot{h}=$ the overall deviation between observed height of sea level and MSS along the track, $S=$ the total length of the track, and $s=$ a single track element between two consecutive positions.

Subtracting $h_{S L}$ by $\Delta h$ shall hence fit both surfaces. However, tide is still presence. We therefore subtract tide from the fitted sea level. For the purpose of the subtraction, tide is obtained from TOPEX/Poseidon crossover solution (TPXO 7.0) global ocean tide model [16]. TPXO 7.0 provides model of sea level oscillation due to tide according to eight primary (M2, S2, N2, K2, $\mathrm{K} 1$, O1, P1, Q1), two long period (Mf, Mm), and three non-linear (M4, MS4, MN4) harmonic constituents. From this, a vertical residual at each position and time is obtained by the following relationship:

$$
\Delta R(\lambda, \varphi, t)=h_{\mathrm{SL}}(\lambda, \varphi, t)-\operatorname{MSS}(\lambda, \varphi)-\dot{h}-T(\lambda, \varphi, t)
$$

with $\Delta R(\lambda, \varphi, t)=$ vertical residual at a given position and time, $t=$ time, and $T(\lambda, \varphi, t)=$ tidal correction at a given position and time. The overall vertical residual along the track $\dot{R}$ is calculated as:

$$
\dot{R}=\frac{1}{S} \int_{0}^{S} R(s) d s
$$

with $\dot{R}=$ the overall vertical residual. 


\section{Results and discussions}

Figure 3 shows model of GGM 02C geoid undulation $N$ in meter above WGS84 reference ellipsoid across the area in question. Figure 4 shows model of MDOT in meter above geoid. Both combines to construct MSS investigated here. One would observe that geoid undulation varies from 17 to $31 \mathrm{~m}$ in the west of Java Sea. Here, MDOT varies only within $0.14 \mathrm{~m}$, from 1.01 to $1.15 \mathrm{~m}$.

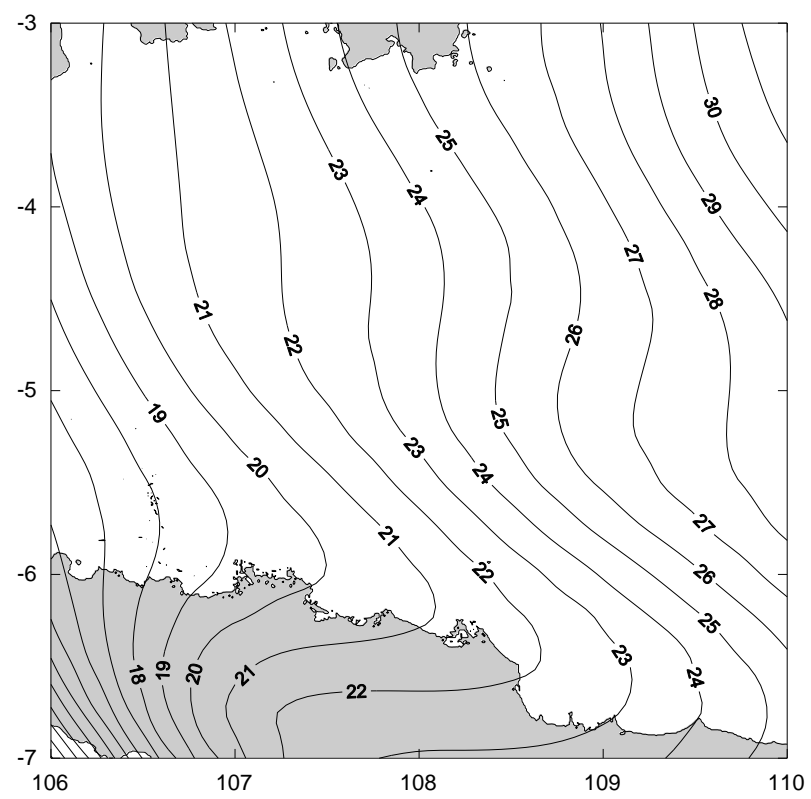

Fig. 3. Geoid undulation $(N)$ generated from 1 ' $\times 1$ ' Gravity Recovery And Climate Experiment (GRACE) Gravity Model (GGM) 02C dataset

The interpolation of geoid undulation $(N)$ and MDOT for the presentation of isolines in Figure 3 and Figure 4 is carried out according to gridding of the respective datasets by using radial basis function [17].

Figure 5 shows the comparison between observed heights of sea level from the GNSS and a global MSS model projected along the longitude. It can be observed that GNSS's sea level is lined up with the trend of the MSS model. With the progressing latitude, GNSS's sea level increases above ellipsoid the way the MSS model does.

In addition to the ellipsoid heights of actual sea level and MSS model, the deviation between GNSS's sea level and the MSS model is also shown in Figure 5. One would see that the deviation vibrates much at short period in the order of decimetre. This might correspond to the uncertainty in GNSS-heighting. In addition to that, it indicates oscillation at a longer period. This longer oscillation has an approximate vertical range of about several decimetres and just less than $1 \mathrm{~m}$, which is typical for the range of tide in the region. We then subtract the deviation with the tide model and expect to obtain non-systematic residual. However, the tide model used here does not seem to fit well with the deviation.

In Figure 6, we show temporal evolution of the fitted sea level, the tide model, and the residual. The fitted sea level is obtained by averaging all sea level height
(Equation 5). In Table 2, the mean deviation between the GNSS's sea level and the MSS is shown as an overall vertical offset $(\dot{\mathrm{h}})$. One would see that in general, the mean height of sea level is somewhat higher than the MSS, by less than $1 \mathrm{dm}$ for C-Nav WA-DGNSS and several decimetres for Trimble NetR9 RTPPP-GNSS.

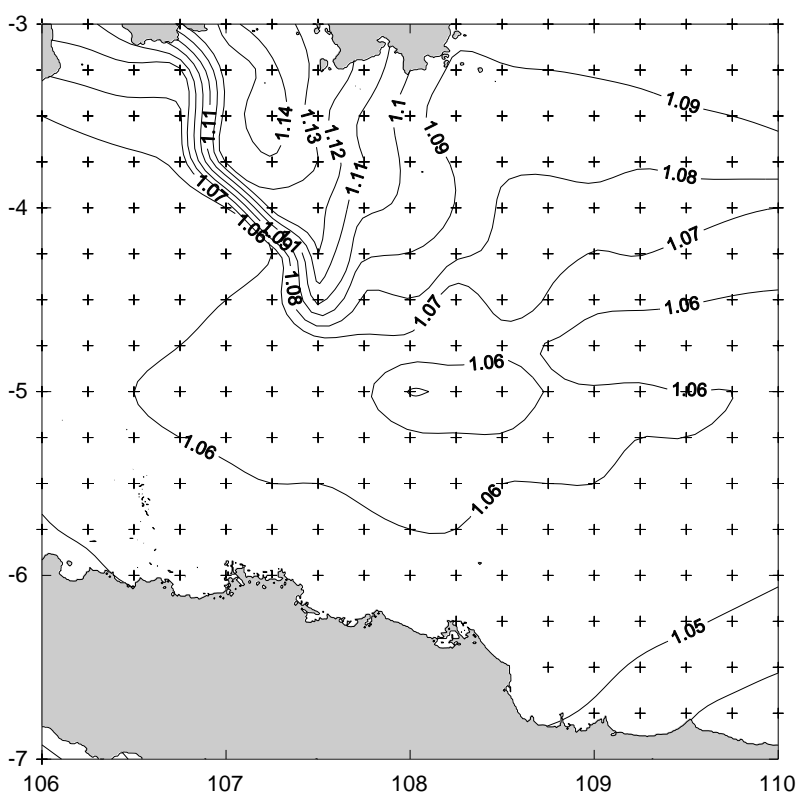

Fig. 4. Mean Dynamic Ocean Topography (MDOT) generated from $0.25^{\circ} \times 0.25^{\circ}$ resolution Asia-Pacific Data Research Centre's dataset

Table 2. Overall vertical offset $(\dot{h})$ between observed sea level and MSS with the corresponding overall residual $(\dot{R})$ and the linear slope of the residual $\left(a_{i}\right)$

\begin{tabular}{|l|c|c|c|}
\hline Method & WA-DGNSS & \multicolumn{2}{|c|}{ RTPPP-GNSS } \\
\hline Device & C-Nav & \multicolumn{2}{|c|}{ Trimble NetR9 } \\
\hline Transit & Away & Away & Return \\
\hline$\dot{h}(\mathrm{~m})$ & 0.075 & 0.395 & 0.36 \\
\hline$\dot{R}(\mathrm{~m})$ & 0.002 & 0.032 & 0.039 \\
\hline$a_{\dot{r}(\mathrm{~m} / \text { day })}$ & 0.089 & 0.085 & 0.109 \\
\hline
\end{tabular}

It can be seen in Figure 6 that the tide model does not fit the observed sea level. Such an indication can be observed from the disagreement between the tide model and the moving average trend of the observed sea level in terms of in their amplitude and phase-lag. As the consequence, the resulting residual still indicate cyclic oscillation due to the inaccurate tidal model subtraction, although their mean values $(\dot{R})$ are quite small, i.e. several $\mathrm{mm}$ for C-Nav WA-DGNSS, several $\mathrm{cm}$ for NetR9 RTPPP-GNSS (see Table 2).

At this present stage, no further effort could be made in looking at a better option of the tidal model. We would formulate this as one of the future work's list. 


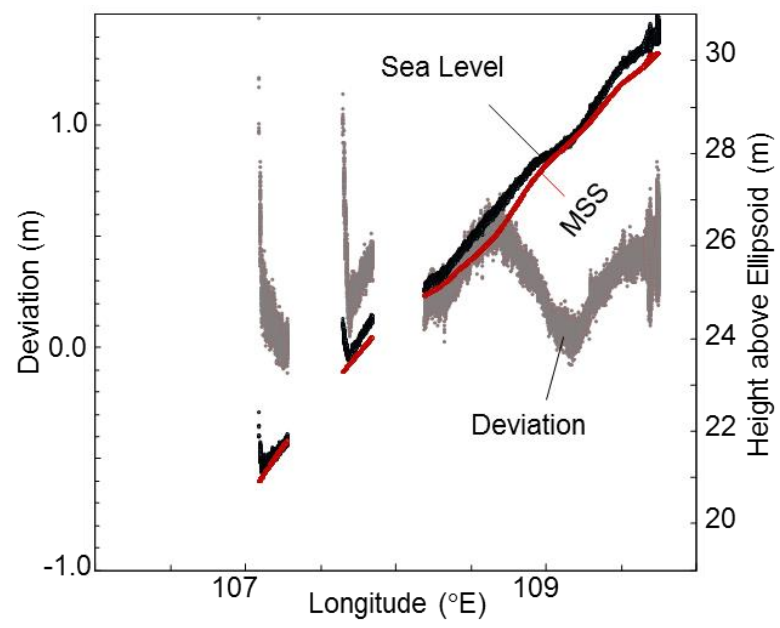

(a) Trimble NetR9 away

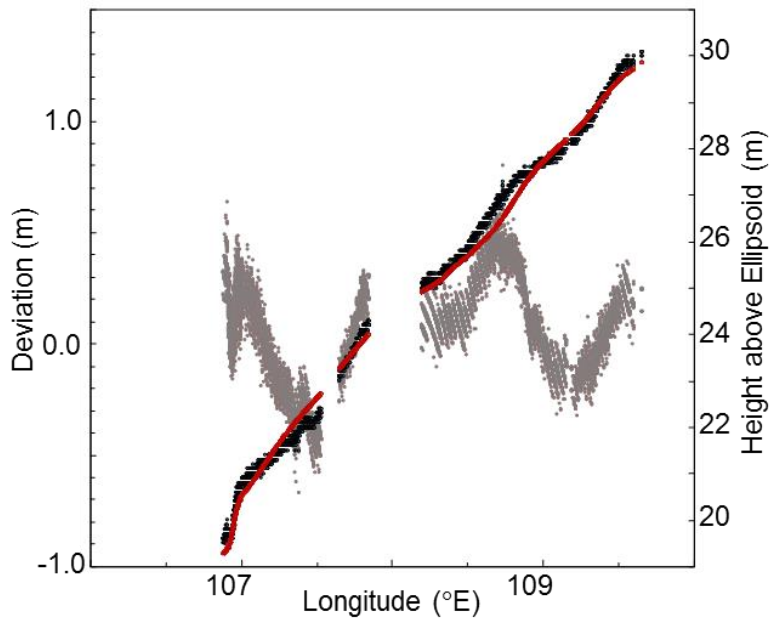

(b) C-Nav away

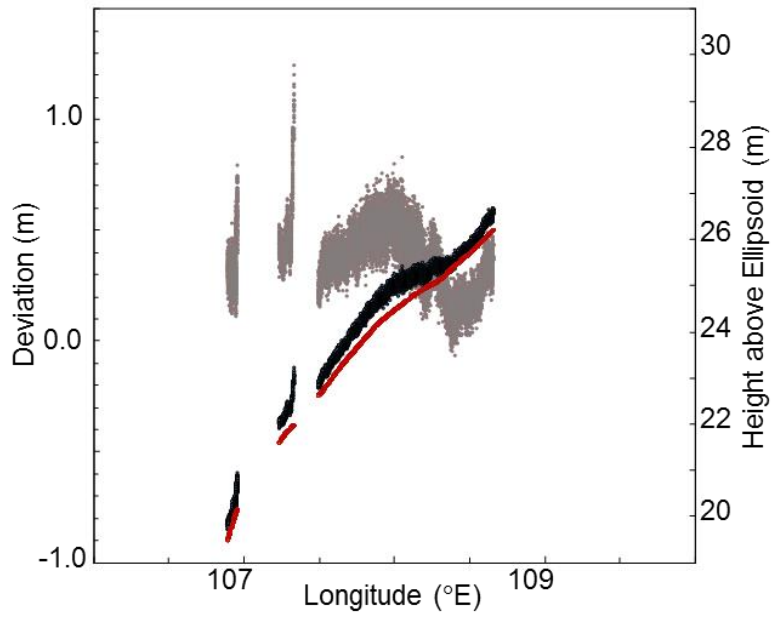

(c) Trimble NetR9 return

Fig. 5. Geodetic height of sea level and Mean Sea Surface (MSS), as well as their vertical deviation over time throughout the cruise projected along the longitude

We also look at the linear trend of the residual as an early attempt to understand its behaviour (see Figure 6). We find out that the residual rises through time by about 8.5 to $11.0 \mathrm{~cm} /$ day. Linear slopes of the residuals are shown in Table 2. This means that within our 5-day mission the corresponding total of vertical rise of residual height can be about close to half of meter. Such a rise could suspiciously be related to the change in the antenna offset, i.e. the vertical separation between antenna level and the sea surface, as we neither provide post-survey check nor regular monitoring (throughout the cruise) of the antenna offset. Such an increase might probably be resulted from the vessel's settlement as it continuously looses weight from fuel and water consumptions.

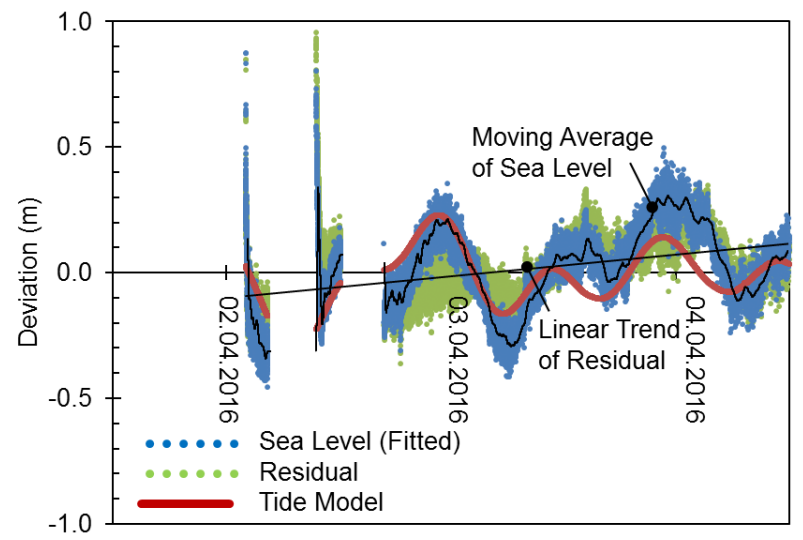

(a) Trimble NetR9 away

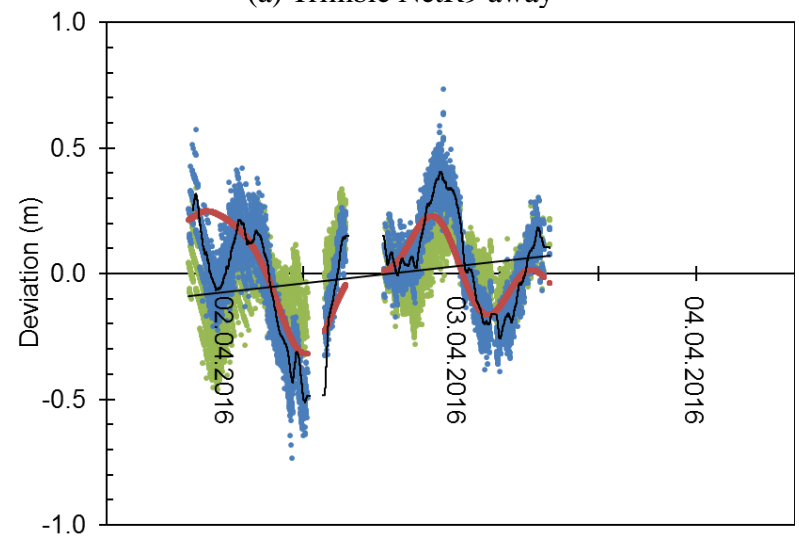

(b) C-Nav away

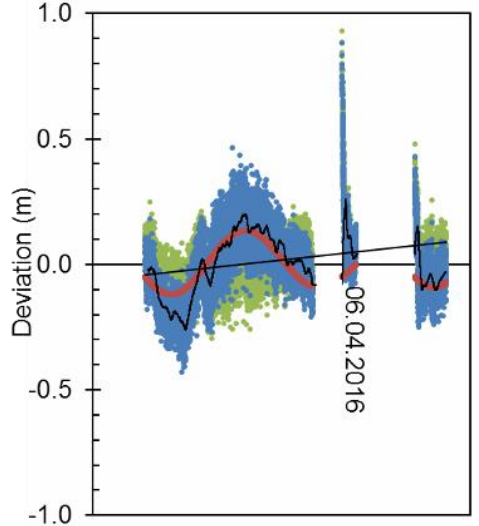

(c) Trimble NetR9 return

Fig. 6. Fitted sea level, tide, and residual across time

However, unless data from regular check of antenna offset or continuous detection of vessel motion is made available, no certain identification of such rises of residual could be elaborated. Because of this, we have to leave it as one essential subject for further improvement of the work. In addition to this, we shall look into the accuracy of the tide model. The improvement of the 
comparison must hence consider a more appropriate study of the tidal oscillation.

\section{Conclusion and recommendation}

GGM 02c and MDOT have enabled the construction of a MSS model for the west of the Java Sea, Indonesia. With this, we have shown the agreement between the MSS model and observed heights of sea level from GNSS according to the direct comparison between them by tracking of geodetic heights of actual sea level using WA D and RTPPP system across about $180 \mathrm{Nm} \mathrm{SW-NE}$ transect. According to the work presented here, the overall agreement between the geodetic height of sea level observed by WA DGNSS and the MSS is $7.5 \mathrm{~cm}$. RTPPP GNSS gives $39.5 \mathrm{~cm}$ and $36.0 \mathrm{~cm}$ overall agreement from away and return tracking.

However, it should be bear in mind that the tide model used here does not fit the oscillated sea level throughout the period of the tracking. This is seen from the disagreement in amplitude and phase-lag between the tide model and the moving average trend of the observed sea level. Hence, the resulting residual contains systematic oscillation due to the application of the tide model. In addition to that, we have noticed that there has been vertical rise of residual height within the time of the tracking. It is thought that the increasing range of GNSS antenna from the sea surface could be one of the contributing reasons. Therefore, selection of the best-fit tide model and careful examination on the dynamics of antenna offset due to vessel attitude are recommended for further studies. Yet, the work exhibits the potential of the use of global model of MSS for the construction of a hydrographic separation model.

Data used in this publication is collected within the framework of a "Collaborative Research on Shallow Sub Seafloor Layers" entitled "Hydroacoustic Profiling for Reconstruction of the Late Pleistocene Landscape in the Java Sea and Spatial Modelling of Sub-tidal Terrain" funded by Amazoko. The authors acknowledged the contribution of Ms Gabriella Alodia, Ms Ajeng Salmayarista, and PT Mahakarya Geo Survey, as well as Surveying and Mapping Laboratory of the Faculty of Earth Sciences and Engineering at the Institute of Technology, Bandung during the fieldwork.

\section{References}

1. J.P. Guyer. An introduction to geodetic reference systems for land surveys. The Clubhouse Press, CreateSpace Independent Publishing Platform, El Macero, California, 54pp (2015).

2. J.D. Bossler, J.B. Campbell, R.B. McMaster, C. Rizos. Manual of geospatial science and technology, Second Edition. CRC Press, 854pp (2010).

3. A.M. Muslim, G.M. Foody. International Journal of Remote Sensing 29(15), 4515-4536 (2008).

4. R. Li, R. Ma, K. Di. Marine Geodesy 25, 27-36 (2002).

5. J.C. Iliffe, M.K. Ziebart, J.F. Turner. The Hydrographic Journal 125, 3-8 (2007).
6. ISO 19901-1. Petroleum and natural gas industries - Specific requirements for offshore structures - Part 1: Metocean design and operating considerations (2015).

7. D. Dodd, J. Mills. International Hydrographic Review, 19-30 (2011).

8. J. Mills, D. Dodd. Ellipsoidally Referenced Surveying for Hydrography. Publication 62. International Federation of Surveyors (2014).

9. D.C. Slobbe, R. Klees, M. Verlaan, L.L. Dorst, H. Gerritsen. Marine Geodesy 36(1) 31-71 (2012).

10. Poerbandono. Assessing risk of navigational hazard from sea-level-related datum in the South West of Java Sea, Indonesia. AIP Conference Proceedings 1857(1) (2017).

11. FIG. FIG guide on the development of a vertical reference surface for hydrography. Guide no. 37. International Federation of Surveyors (2006).

12. B.D. Tapley, S. Bettadpur, M. Watkins, C. Reigber. Geophysical Research Letter 31 (2004).

13. B.D. Tapley, F. Flechtner, M. Watkins, S. Bettadpur. GRACE mission: status and prospects. The GRACE Science Team Meeting (2015).

14. N. Maximenko, P. Knudsen, L. Centurioni, O. Andersen, J. Hafner, O. Melnichenko. New Mean Dynamic Ocean Topography Derived from a Synthesis of Satellite Altimeter, Gravity, and Scatterometer Data and Trajectories of Lagrangian Drifters. Ocean Surface Topography Science Team Meeting (2014).

15. D. Pugh, P. Woodworth. Sea level science: Understanding tides, surges, tsunamis, and mean sea level changes. Cambridge University Press (2014).

16. G.D. Egbert, S.Y. Erofeeva. Journal of Atmospheric and Oceanic Technology 19(2) 183-204 (2002).

17. R.E. Carlson, T.A. Foley. Computers and Mathematics with Applications 21(9) 29-42 (1991). 